\title{
Explaining recent increases in calorie intake in rural India: the role of social policy strengthening
}

\section{Bill Pritchard, Kuntala Lahiri-Dutt \& Md Zakaria Siddiqui}

To cite this article: Bill Pritchard, Kuntala Lahiri-Dutt \& Md Zakaria Siddiqui (2019) Explaining recent increases in calorie intake in rural India: the role of social policy strengthening, India Review, 18:2, 161-183, DOI: 10.1080/14736489.2019.1605121

To link to this article: https://doi.org/10.1080/14736489.2019.1605121

\section{Published online: 01 May 2019.}

\section{Submit your article to this journal $\longleftarrow$}

џll Article views: 131

Q View related articles $\sqsubset$

View Crossmark data \lceil 


\title{
Explaining recent increases in calorie intake in rural India: the role of social policy strengthening
}

\author{
Bill Pritchard, Kuntala Lahiri-Dutt, and Md Zakaria Siddiqui
}

\begin{abstract}
During the past decade, considerable research efforts have sought to explain India's "calorie consumption paradox", namely, the coexistence of a decline in average per capita calorie intake in rural India alongside increased material living standards. Evidence from the most recent (68th) round of the National Sample Survey (NSS), released in 2014, however, indicates increases in calorie intake, notably among poorer income quintiles. This paper argues that the turnaround in these data is linked to the improved performance of pro-poor social protection measures. Analysis of data suggests a close association between states that have made the greatest improvements in social policy delivery systems, and increased calorie intake for the poorest quintile of rural populations. This conclusion supports wider international evidence on the importance of social protection strengthening for nutritionsensitive economic growth.
\end{abstract}

\section{Introduction}

The debate on calorie intake and poverty in India is internationally important. Since the onset of India's liberalization policies from 1991, economic growth has quickened and the poverty ratio has fallen, ${ }^{1}$ albeit within contexts of large and rising levels of inequality. ${ }^{2}$ Nevertheless, for the first two decades of postliberalization India, evidence suggested that economic growth and poverty reductions encompassed a calorie consumption paradox; per capita calorie intake was actually falling for all segments of the population, including the poorest. ${ }^{3}$ India's economic transformation, it seemed, was not delivering a robust dividend in terms of improved food consumption, and the nutritional indicators (notably child stunting and wasting) that are associated with increased calories being consumed by the poor. ${ }^{4}$ This was unlike the situation in other Asian countries, where economic growth was associated with strong improvements in nutrition indicators, as discussed in the next section.

Data released in the past few years from large-scale surveys conducted between 2011 and 2014, however, suggest a compelling narrative of calorie consumption turnaround, in particular for the poor. The most important of these surveys is the 
68th round of the National Sample Survey (NSS) conducted in 2011/12, with results published in 2014. This survey covered over 100,000 households. Evidence of improved nutritional indicators is also apparent from the "HUNGaMA" (Hunger and Malnutrition) survey of India's 100 poorest districts conducted in 2011, the fourth District Level Health Survey (DLHS-IV) conducted from 2012 to 2014, the second India Human Development Survey (IHDS-II) of 2011/12, and the Comprehensive Nutrition Survey of Maharashtra. ${ }^{5}$

This newer evidence compels development studies scholars to consider the drivers of this turnaround. Not surprisingly, this is a complex and difficult undertaking. Rural India is home to a population with hugely diverse human and environmental circumstances that encompass manifold differences in terms of food cultures and relationships to local agro-ecosystems, labor markets, infrastructure, and government services. Nevertheless, we contend that it is possible to see evidence of broad politico-economic transformations in rural India in the calorie consumption turnaround.

Our argument is that increases in calorie intake and improved nutritional indicators bear the imprint of reforms to food-based social protection schemes, notably the Public Distribution System (PDS). In recent years, a number of state governments have given political priority to improving the PDS. These reforms have been complemented by wider social policy strengthening, including the rolling out of the Mahatma Gandhi National Rural Employment Guarantee Act (MGNREGA), improvements to the Integrated Child Development Scheme (ICDS), ${ }^{6}$ the Midday Meal Scheme and nutrition-specific programs such as the Maharashtra Comprehensive Nutrition Program. ${ }^{7}$ Although these initiatives were all highly uneven in their geographical and social coverage, nevertheless they played an important role overall. In emphasizing these social protection themes, we contribute to recent global scholarship into food and nutrition security that contends that "economic growth is necessary but not sufficient to accelerate reduction of hunger and malnutrition", ${ }^{8}$ hence challenging neo-liberalist accounts, such as the so-called Dollar-Kraay thesis, ${ }^{9}$ that scorns the advocacy of redistributive welfare measures for pro-poor outcomes, in favor of a narrower focus on economic growth.

\section{India's post-liberalization calorie consumption paradox}

During the 1990s and into the 2000s, an Indian economic narrative was scripted which emphasized material progress and national self-confidence. However, with the release of data from the $61^{\text {st }}$ Round of the NSS, covering the period 2004/05, statistics of calorie consumption presented in sharp relief a very different reality that seemed to be playing out in India's villages. The data estimated that mean per capita calorie consumption in rural India was 2,047 kcal, representing a decline from the levels recorded in 1999/2000 $(2,148 \mathrm{kcal}), 1993 / 94(2,153 \mathrm{kcal}), 1987 / 88(2,233 \mathrm{kcal})$ and $1983(2,240$ 
kcal). ${ }^{10}$ Whereas in $1983,66.1 \%$ of the rural India's population lived in households where per capita calorie consumption was less than 2,400 kcal per day, by $2004 / 05$, this had increased to $79.8 \%{ }^{11}$

As these data came to light, the concept of the "Indian calorie consumption paradox" was coined and a flurry of research efforts took place seeking to explain these outcomes. The starting point for this debate was international evidence published by the World Bank ${ }^{12}$ which suggested a rule-of-thumb for the relationship between economic growth and improvements to childhood stunting and wasting. As summarized by Pritchard et al., ${ }^{13}$ in the take-off stages of economic growth, the prevalence of children underweight for age typically fell by "roughly half the rate of GDP growth. Thus, if an economy's annual growth averages $4 \%$ over a decade, the prevalence of child underweight for age would be expected to fall by $2 \%$ annually." More recent research into this relationship has asserted an elasticity of 0.6 for child stunting (low height for age), meaning that if GDP increases by $10 \%$, the proportion of stunting would be expected to fall by $6 \% .{ }^{14}$ Research by Gillespie and Kadiyala ${ }^{15}$ however demonstrated that in India, international benchmarks for the relationship between economic growth and improved nutrition failed to apply. Between 1990 and 2005, reductions in child underweight for age in India fell at less than half the rate than anticipated by the international rule-of-thumb. Although caveats must be observed in equating childhood stunting and wasting with calorie consumption data, these indicators tell a parallel and consistent story.

Recognition of India's poor nutritional performance prompted diverse debate. Contributions raised questions both about the accuracy of data being reported, and the relative influence of socio-economic, dietary and physiological variables in determining apparent outcomes.

\section{The accuracy of data?}

The capture of accurate food consumption and income-expenditure data in the rural Indian context is a notoriously difficult exercise. Methodological concerns have been a bone of contention for decades. These concerns have been heightened in the post-liberalization era when estimates of aggregate consumption generated by India's National Accounts System (NAS) have tended to be much higher than those from the National Sample Survey (NSS). ${ }^{16}$ The potential for divergence between these two data sources is because they derive estimates of consumption in fundamentally different ways, and are therefore susceptible to different sources of bias. ${ }^{17}$ These differences are not insignificant. In 2009/10, the NAS was estimating food consumption levels $40 \%$ higher than those reported by the NSS. ${ }^{18}$ Review of these issues by the Rangarajan expert group on poverty measurement, a committee established by the Planning Commission of India in 2012, 
affirmed the legitimacy of the lower estimates of consumption produced by the NSS. ${ }^{19}$

Nevertheless, uncertainty about trends over time has festered because of changes to NSS methodologies between surveys. Until the 1993/94 survey, all consumption estimates were derived on the basis of a 30-day recall period. From $1994 / 95$ to 1998/99 in the "thin" (or small sample size) sample surveys, NSSO experimented with two types of schedule - one based on the usual 30-day recall and another based on a 7-day recall for food items. This methodological change generated higher estimates of food consumption (i.e., respondents tended to report higher daily amounts in the shorter recall periods of 7 days compared to the 30-day recall period). However, the relative standard error of these estimates was also higher and the estimates for the first week of every month were higher than other weeks. ${ }^{20}$ Given these concerns, the "thick" (large sample consisting of more than 100,000 households) round of 1999/2000 was designed to record consumption of each food item according to both a 7 day and 30 day recall period. Questions regarding both recall periods were compiled as columns for each commodity. This change in the reporting method, however, created an inconsistency with previous data series. The presence of both recall periods caused confusion for respondents, with responses for one period potentially biasing the other. Thus, for the 2004/05 survey, the NSS reverted to a 30-day recall period. From then on, later "thick" rounds (2009/10 and 2011/12) had two independent surveys: one on the basis of the usual 30-day recall period (covering consumption of all items (i.e., food and non-food)); the other on the basis of a 7-day recall period for food items that are frequently consumed. The net conclusion to be made from these episodes of change is that the NSS estimates should be considered as providing a valid estimation of food consumption, so long as comparisons between survey periods are done using data series that were derived from the same methodological approaches.

\section{Social and economic explanations}

Focusing on social and economic explanations for these results, it is possible to distill four lines of argument in the debate on India's calorie consumption paradox. The first of these relates to lower daily dietary energy requirements in the rural population. This is the focal argument of Deaton and Dréze, ${ }^{21}$ who suggest firstly, that in rural India, mechanization in agriculture and the construction industry, increased the availability of motorized transport, the availability of processed food grains, and improved kitchen appliances have all helped reduce individual activity levels and thus individual calorific requirements. As a result, they contend there is a downward shift in the calorie Engel curve (logarithm of calorie per capita plotted against the logarithm of Monthly Per Capita Expenditure [MPCE]) over time. This hypothesis was further supported by Eli and $\mathrm{Li}^{22}$ who claim that 
a substantial portion of the decline in calorie consumption can be explained by changes in physical activity levels.

The second line of argumentation revolves around the costliness of food items and a food budget squeeze facing households. Basole and Basu ${ }^{23}$ establish that the burden of expenditure on non-food essentials has led to a squeeze on food budgets. This is especially the case for fuel expenditure, as prices relative to food have increased over time. Siddiqui and Chakraborty ${ }^{24}$ also find that many families in rural Bihar and Jharkhand have become used to eating cooked meals only once a day (mostly in the evening) to economize on fuel costs. For other meals, they depend on the readymade cereal/pulses-based meal sattu.

These considerations are connected to Banerjee and Duflo's ${ }^{25}$ more general argument derived from behavioral economics that poor people might intentionally exchange the benefits of additional calories for other expenditures that are perceived as having more immediate, dependable or enjoyable benefits. This helps explain why many poor people devote relatively high expenditures to status and comfort goods, in contexts where the future benefits from increased calories are marred with uncertainties. The role of India's dietary and culinary traditions is much debated within these frames. In other parts of the world, reduced per capita consumption of cereals often tends to be associated with increased overall calorie intake as households substitute cereal-dominated diets with increased dietary diversity, including larger amounts of fruits, vegetables and in particular, protein-rich animal foods. In rural India however, these processes are refracted through a much more complex and differentiated social and cultural landscape. Food choice is dictated for many rural Indians by dietary norms and taboos. This is most apparent regarding vegetarianism but is also manifested in an array of cultural practices connected to seasonal and festival events. The importance of these factors has been highlighted most forcefully by Landy, ${ }^{26}$ who contends that India's distinctive culinary and dietary traditions ensure its food transitions take a different shape from elsewhere in the world. This is an issue that is not easily resolved. Social and cultural factors endemic to rural India evidently make it "different", but the extent to which this difference is a determining factor of the calorie consumption paradox is difficult to establish. For example, evidence from the 68th round of the NSS (2011/12, made available only after Landy's ${ }^{27}$ publication) indicates that vegetarian households have higher per capita calorie consumption than nonvegetarian households, within all income quintiles and in both urban and rural areas (Table 1). Evidently, the absence of meat in diets is not associated with lower calorie intake.

A third broad line of argumentation relates to PDS failures. During the 1990s and early 2000s, an extensive body of evidence was amassed that documented widespread maladministration and pilferage riddled through the PDS. Bhalla ${ }^{28}$ suggests that the $1999 / 2000$ NSS data indicate that just $29 \%$ of the allocated 
Table 1. Calorie consumption per capita of vegetarian and non-vegetarian items, 2011/12.

\begin{tabular}{lccccc}
\hline & \multicolumn{2}{c}{ Rural } & & \multicolumn{2}{c}{ Urban } \\
\cline { 2 - 3 } \cline { 5 - 6 } Quintile & $\begin{array}{c}\text { Consumed non- } \\
\text { vegetarian items }\end{array}$ & $\begin{array}{c}\text { Consumed only } \\
\text { vegetarian items }\end{array}$ & & $\begin{array}{c}\text { Consumed non- } \\
\text { vegetarian items }\end{array}$ & $\begin{array}{c}\text { Consumed only } \\
\text { vegetarian items }\end{array}$ \\
\hline 1 & 1747 & 1750 & 1694 & 1703 \\
2 & 1927 & 2115 & & 1884 & 1891 \\
3 & 2053 & 2271 & & 2001 & 2036 \\
4 & 2200 & 2574 & & 2462 & 2221 \\
5 & 2458 & 2143 & & 2021 & 2583 \\
Total & 2074 & & & & 2120 \\
\hline
\end{tabular}

Source: Calculated from NSS 68th round consumption expenditure survey data. Note: includes vegetarian and non-vegetarian households.

foodgrains reached beneficiaries. According to the Planning Commission of India, ${ }^{29} 42 \%$ of subsidized food grains reached their intended target group. Jha and Ramaswami ${ }^{30}$ argued that in $2004 / 05,40 \%$ of the PDS rice and $73 \%$ of the PDS wheat were pilfered. Whatever the actual numbers, it was clear that the poor performance of the PDS during the 15 years or so after the liberalization reforms of 1991 meant that social protection measures played an underwhelming role in India's nutritional challenge.

Fourth and finally, there is the issue of whether meals eaten outside the home are fully captured in calorie consumption data. Smith ${ }^{31}$ advances an argument that, at least in part, the NSSO data has not been able to fully account for cooked meals that individual members of the households receive in kind or in exchange of cash and also as assistance meals, e.g., mid-meal in schools and meals provided by employees. Since this component has been increasing over time and if NSS systematically underreports this component of food consumption, it is likely that fall in calorie consumption may be attributed at least partly to this unobserved component. Gaiha, Jha, and Kulkarni ${ }^{32}$ use another nationally representative survey (the India Human Development Survey (IHDS)) conducted in 2005 to show much higher incidence ( $28 \%$ of the households) of eating purchased meals than NSS survey (6\% of the household) conducted in 2004-05. Specifically, urban slum residents have a very high incidence $(46 \%)$ of eating purchased meals according to IHDS data, probably because of many households do not have kitchens and working hours for members of these households extremely high. Smith ${ }^{33}$ also shows that the countries that follow diary methods of collecting information regarding food items report systematically higher calorie intake than countries that do not follow this method including India.

In summary, there is no clear single explanation for India's calorie consumption paradox in the post-liberalization period, however various major contextual drivers can be identified. Pritchard, Rammohan and Sekher ${ }^{34}$ theorize these issues in terms of a series of mutually-reinforcing entitlement failures for food that confronted rural India's poor populations in this period. Whatever the precise contribution of factors, the key concern for this paper is that something changed to catalyze a turnaround in calorie consumption trends as revealed by 
the 2011/12 NSS results. We now address the dimensions of this turnaround and move toward the identification of potential associative factors.

\section{Evidence of a calorie consumption turnaround}

Our contribution to the debate on the Indian consumption paradox primarily involves assessment of data for rural India from the 68th round of the National Sample Survey (NSS), covering the period 2011/12. The method we use is to analyze calorie consumption levels for carbohydrates, protein, and fats, disaggregated by states, income quintiles, and PDS categories. Calorie consumption levels are estimated from sample households' information on consumption quantities for an exhaustive of a list of food items, converted into calorie, fat and protein equivalents, using the framework presented in NSSO. ${ }^{35,36}$ These calculations enable us to estimate carbohydrate content of each item as a residual from total calorie content after subtracting protein and fat.

Our analysis of these data indicates a turnaround in calorie consumption trends. As indicated in the last column of Table 2, total per capita calorie intake in rural India fell during the two periods 1972/73 to 1993/ 94, and $1993 / 94$ to $2004 / 05$, but then increased in the period $2004 / 05$ to 2011/12. Analysis of this reversal by income quintiles (Figure 1 and Table 2) provides important insights into the drivers of this change. In the preliberalization period (1972/73 to 1993/94), there was rapid convergence of per capita calorie intakes by quintile on account of a significant fall in calorie intake of the top quintile (quintile 5) and increased calorie intake of the poorest two income quintiles (quintiles 1 and 2). During the middle period (1993/94 to 2004/05), however, increased per capita calorie intake for the poorer quintiles stalled and, in combination with continuing reductions in per capita intake for richer quintiles, led to an overall reduction in rural India's per capita calorie intake. As discussed previously, the coincidence of this with more rapid economic growth inspired conceptualization of India's nutrition situation in terms of a calorie consumption paradox.

The inclusion of the 2011/12 data, however, challenges the narrative of a calorie consumption paradox. The trend in per capita calorie intake between 2004/05 and 2011/12 corresponds more closely to expectations. These data show

Table 2. Compounded annual growth of per capita calorie intake by economic (quintile) classes in rural India (percentage).

\begin{tabular}{rrrrrrr}
\hline & 1 & 2 & 3 & 4 & 5 & Total \\
\hline $1972 / 73$ to $1993 / 94$ & 0.62 & 0.11 & -0.11 & -0.33 & -0.86 & -0.23 \\
$1993 / 94$ to $2004 / 05$ & 0.07 & -0.17 & -0.27 & -0.27 & -0.56 & -0.46 \\
$2004 / 05$ to $2011 / 12$ & 1.05 & 0.45 & 0.16 & -0.26 & -0.66 & 0.31 \\
\hline
\end{tabular}

Sources: For 1972/-73 Suryanarayana, ${ }^{37}$ for the remaining years it was calculated from NSS 50th, 61st, and 68th round consumption expenditure reports. 


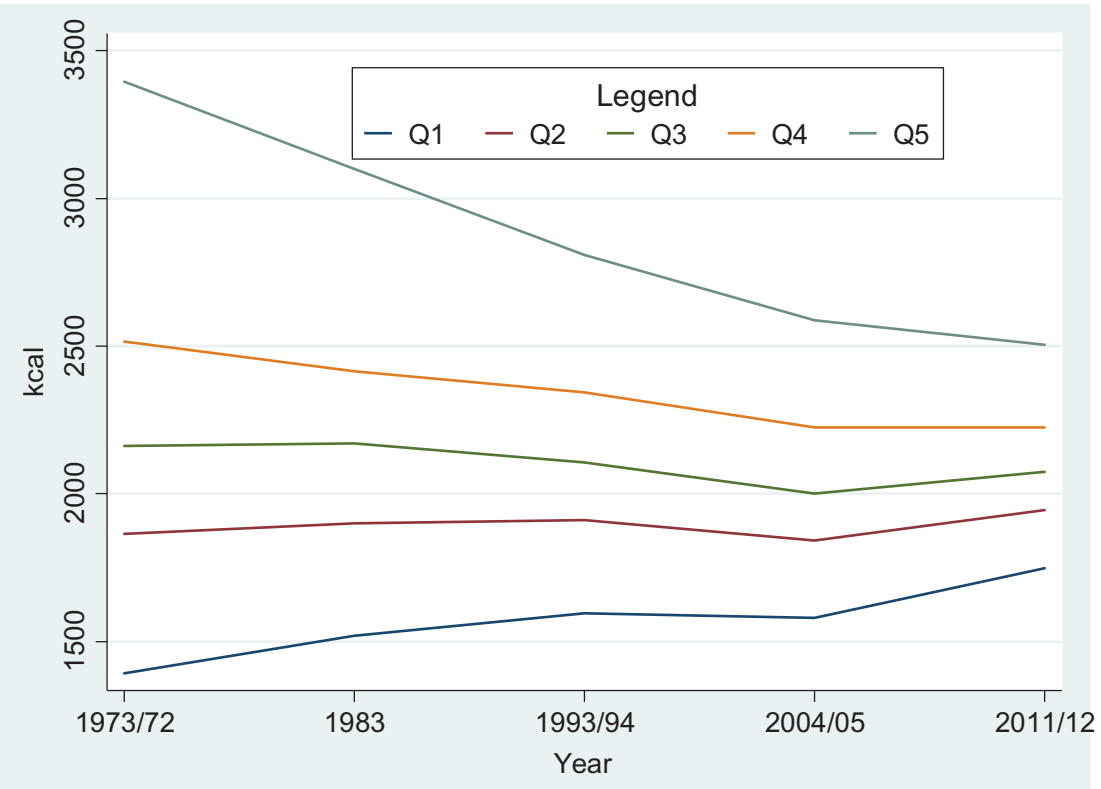

Figure 1. Trend of per capita calorie consumption across economic class (quintiles) in rural India. Sources: For 1972/-73 Suryanarayana, ${ }^{38}$ for the remaining years it was calculated from unit level data of 50th, 61st, and 68th round consumption expenditure.

a clear pattern of change, with growth strongest for the lowest quintile and becoming sequentially weaker for each higher quintile. That is, the dynamic of calorie consumption in the post 2004/05 period displays a classic pro-poor orientation, with the poorest and most food-deprived quintiles making strongest gains, and the richest quintiles continuing a trend of lower per capita consumption, no doubt reflecting the driver of lower dietary energy requirements, especially for richer people less likely to be involved in manual labor, identified by Deaton and Dréze, ${ }^{39}$ discussed above.

Evidence of an apparent turnaround in Indian calorie consumption indicators, however, raises the further question of how these trends are related to dietary shifts. One perspective that can be used to glean insights here involves disaggregating the trends in Figure 1 and Table 2 into the dietary components of carbohydrates (Figure 2), protein (Figure 3) and fats (Figure 4). Comparison of these three graphs shows rapid convergence among quintiles of per capita intake for carbohydrates and (to a lesser extent) protein, and rapid growth of fat intake across all quintiles.

The rapid convergence in carbohydrate consumption among quintiles is the key driver of broader trends in consumption, as this dietary component accounts for more than two-thirds of total per capita calories. As seen readily in Figure 2, between 2004/05 and 2011/12 there was a noticeable increase in per capita carbohydrate consumption among the poorest quintile, which as discussed below provides strong evidence of increased cereals consumption 


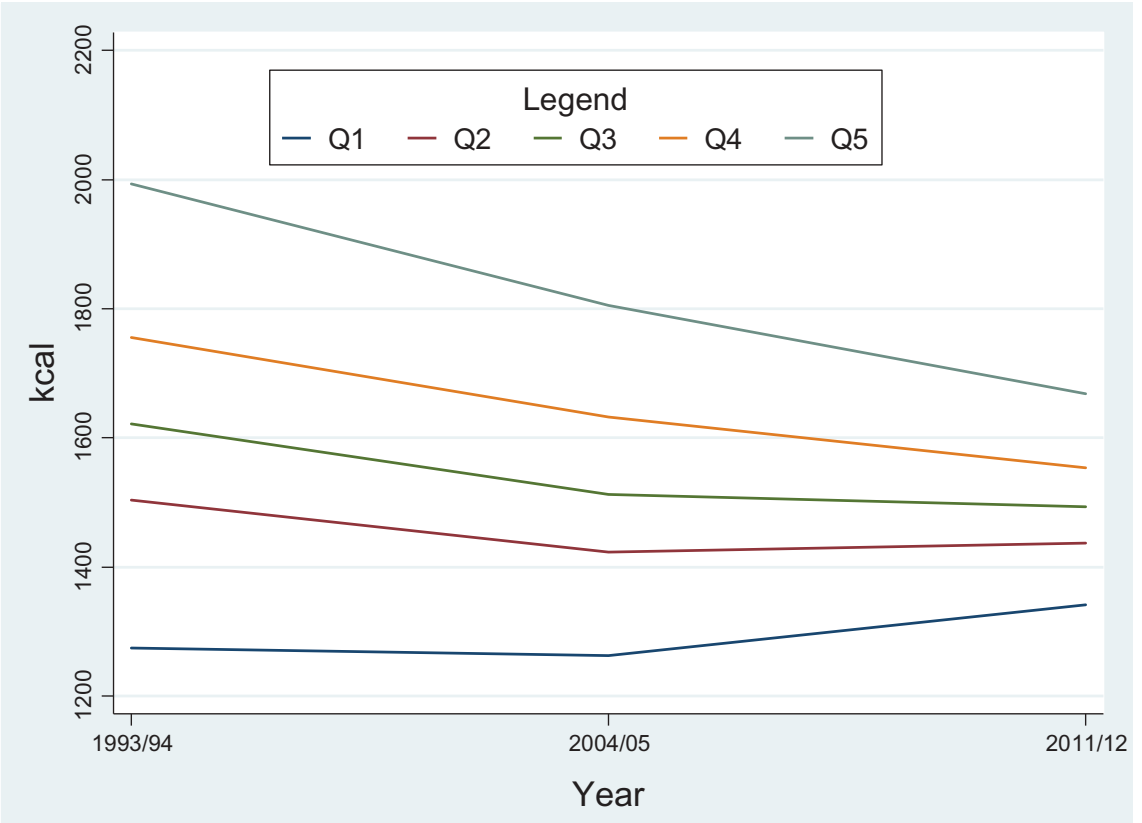

Figure 2. Per capita daily carbohydrate intake by economic (quintile) classes in 1993/94, 2004/05 and 2011/12 for rural India. Source: Calculated from NSS unit level data of 68th, 61st and 50th round on consumption expenditure.

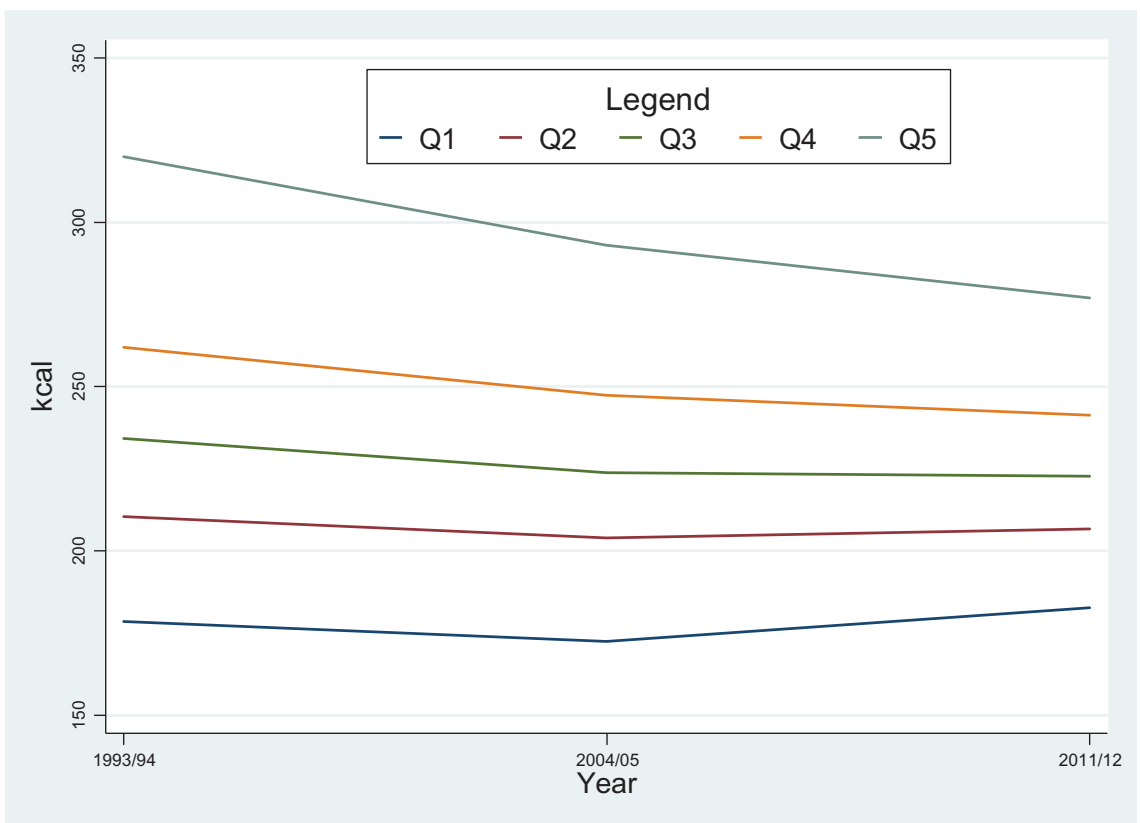

Figure 3. Per capita daily protein intake by economic (quintile) classes in 1993/94, 2004/05 and 2011/12 for rural India. Source: Calculated from NSS unit level data of 68th, 61st and 50th round on consumption expenditure. 


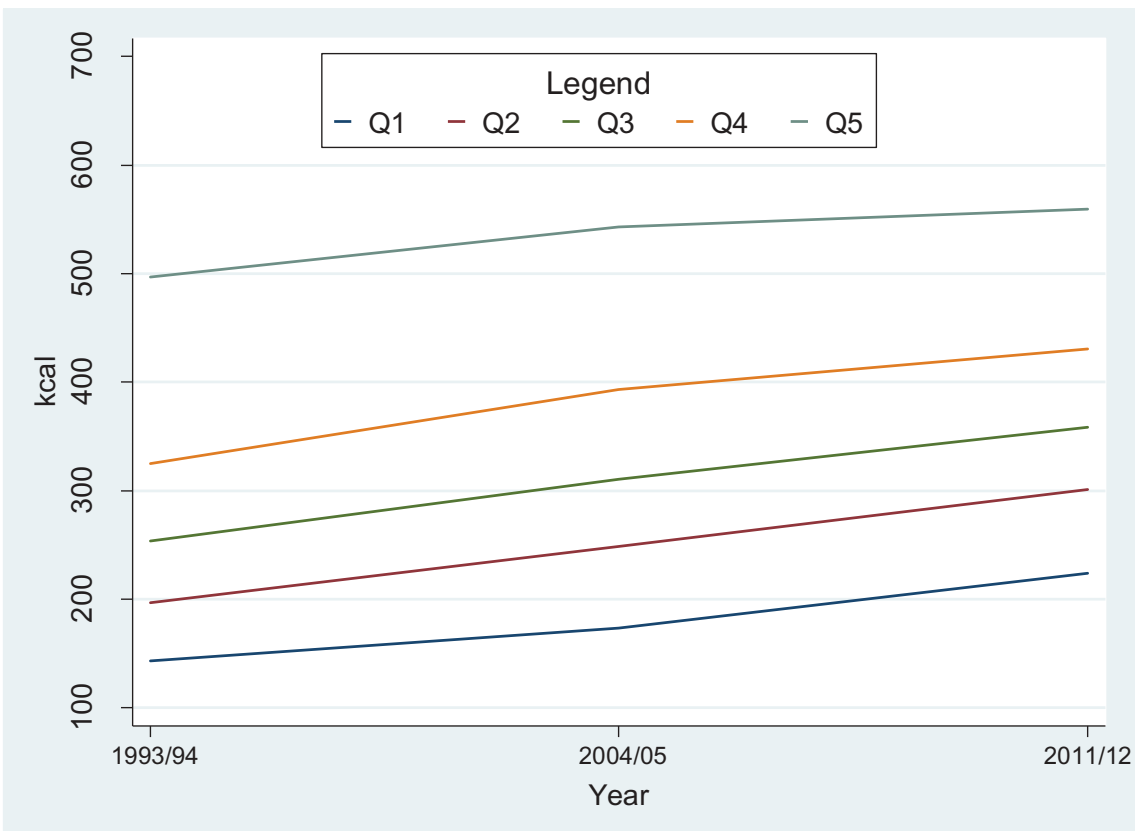

Figure 4. Per capita daily fat intake by economic (quintile) classes in 1993/94, 2004/05 and 2011/ 12 for rural India. Source: Calculated from NSS unit level data 68th, 61st and 50th round on consumption expenditure.

with particular reference to PDS-supplied rice and wheat. A similar pattern is displayed for per capita protein consumption (Figure 3), potentially linked to increased pulses and meat consumption (for non-vegetarians) among the poor. These data point to an interesting variant on narratives of declining pulse consumption in India - evidently, this appears valid for richer quintiles but not among the poorest. The fact that the poorest quintile has increased its per capita consumption of protein at a time when this has fallen for other (richer) quintiles is suggestive of significant nutritional improvements in the lives of the poor, as protein foods to be relatively expensive components of diets. Finally, Figure 4 points to increased fats consumption across all quintiles, which would appear to be symptomatic of a transition in food intake that has a high proportion of edible oils. There is a transition that is more focused on snacking deep-fried vegetarian items like samosas and puris, which, according to these data, is pervasive across income quintiles. Although outside the strict focus of this paper, increased fat consumption is implicated in a higher prevalence of overweight/obesity and noncommunicable diseases across the country.

The apparent turnaround in per capita calorie consumption for the poorer quintiles also has a distinctive state-wise component. In Figure 5, and the charts that follow, per capita calorie consumption for individual states is compared against two time periods. ${ }^{40}$ The vertical distance between the 45 -degree line (the 

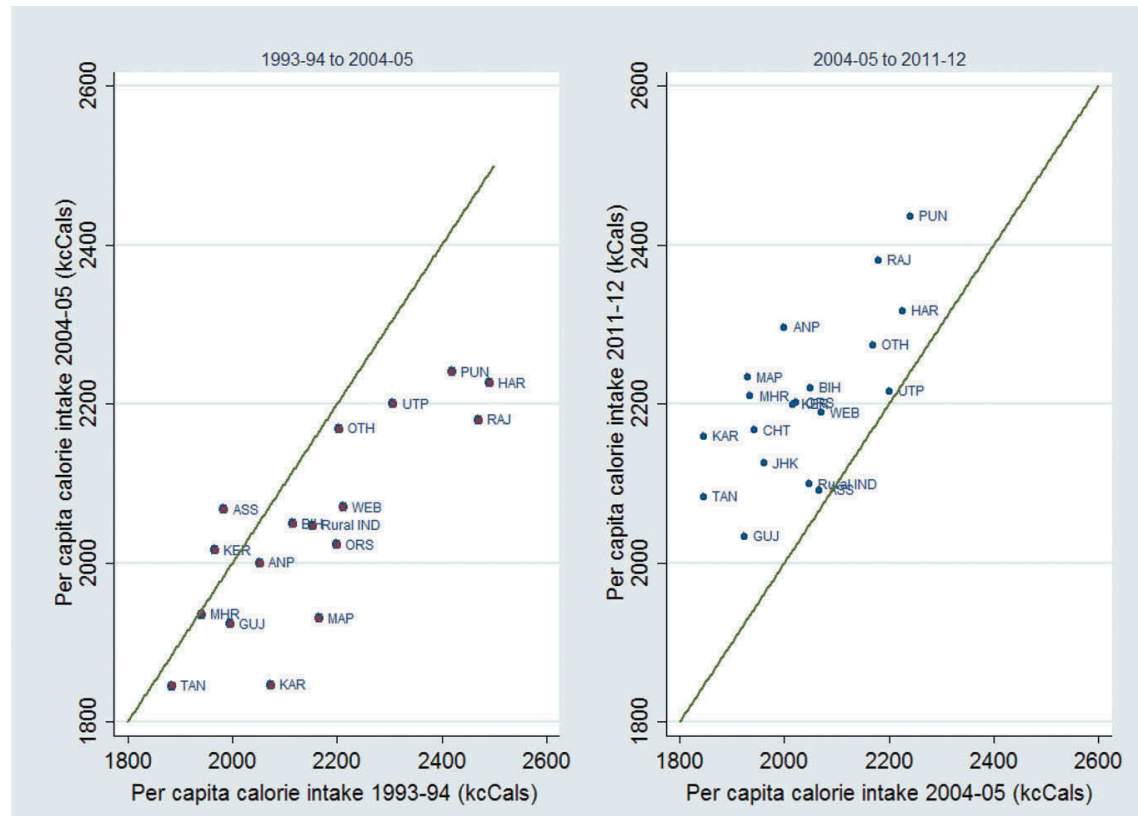

Figure 5. Average per capita calorie intake by major states in rural India from 1993/94 to 2011/ 12. Note: The vertical distance between the 45 -degree line (the line of equality), and a point for a state shows the amount of change in per capita calorie intake for that state between the two time periods. Source: Calculated from NSS unit level data of 68th, 61st and 50th round on consumption expenditure.

line of equality) and a point for a particular state shows the amount of change in per capita calorie intake for that state between the two time periods. Points below the line of equality imply that the per capita calorie intake for an individual state has fallen. Points above the line of equality indicate they have increased. In Figure 5, therefore, it is apparent that between 1993/94 and 2004/05 (the left chart), per capita calorie consumption declined for most states. However, from 2004/05 to 2011/12 (the right chart), the opposite was true (as also indicated in Table 2, discussed previously).

Figure 5 shows that the states with the greatest improvements in per capita calorie consumption between 2004/05 and 2011/12 (the data points furthest from the line of equality) were Tamil Nadu, Karnataka, Madhya Pradesh, Maharashtra, Chhattisgarh, and Andhra Pradesh (See the Appendix for acronyms of state used in the Figures 5-8). This group comprises what would appear at first glance to be a diverse collection of states, with very different characteristics and levels of development. However, as elaborated upon below, closer inspection of their recent histories bears out striking insights.

To complement Figure 5, which presents state-wise averages, Figures 6 and 7 display the change in per capita calorie consumption for the top and 

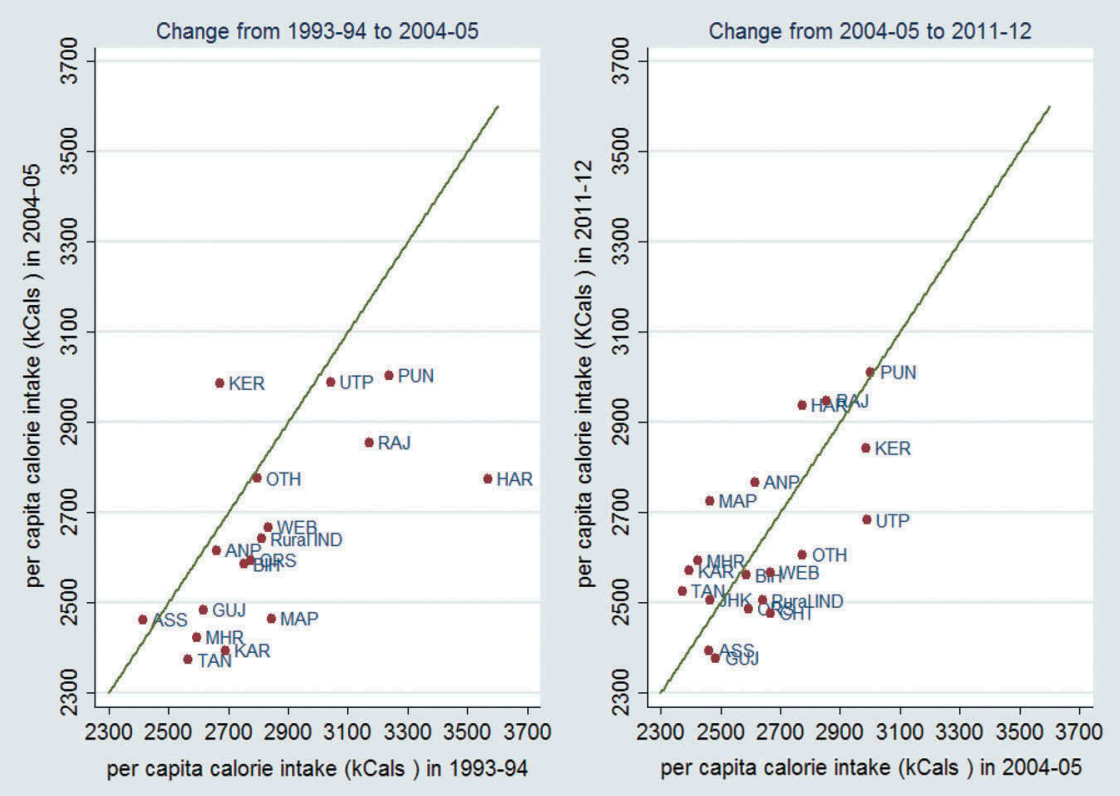

Figure 6. Calorie intake of the top (richest 20\%) quintile of major states of rural India, 1993-94 to 2011-12. Source: Calculated from NSS unit level data of 68th, 61st and 50th round on consumption expenditure.

bottom quintiles of each state, for each of the two time periods (1993/94 to $2004 / 05$ and 2004/05 to 2011/12) under consideration. Focusing firstly on the richest quintile (Figure 6), per capita calorie consumption fell in all states except Kerala and Assam in the period from 1993/94 to 2004/05. In the second period, however, the state-wide pattern was very different, with roughly equal numbers of states experiencing increased and decreased levels of per capita calorie consumption. It is difficult to interpret the reasons for this scattered pattern in the more recent period of analysis. Disaggregation of these data by the key dietary components of fats, carbohydrates, and protein does not provide a ready explanation, suggesting that the answer would seem to lie in the fact that modernity, dietary change and culinary cultures are intersecting in complex and differentiated ways within the richest $20 \%$ of the rural India's population.

For the purposes of this paper, trends for the poorest quintile are of greater interest than those for the richest $20 \%$, as this links more directly to arguments about the calorie consumption paradox. As seen in Figure 7, during the period 1993/94 to 2004/05, states were split almost evenly between those registering an increase in per capita calorie consumption among their poorest $20 \%$, and those registering a fall. In the latter period, however, the poorest quintile of all states registered an increase in per capita calorie consumption, with increases being largest in Odisha, Tamil Nadu, Andhra 

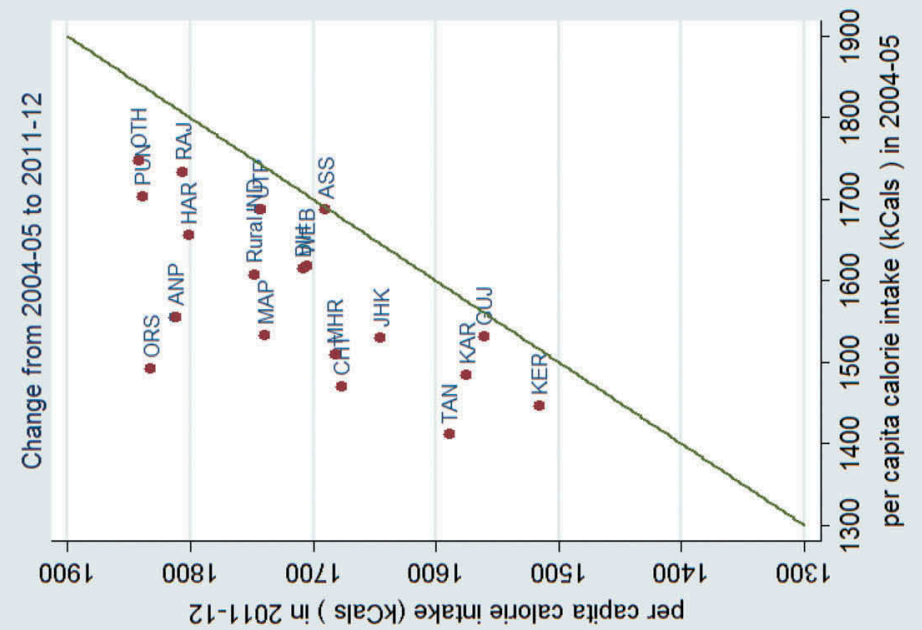

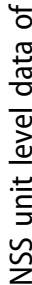
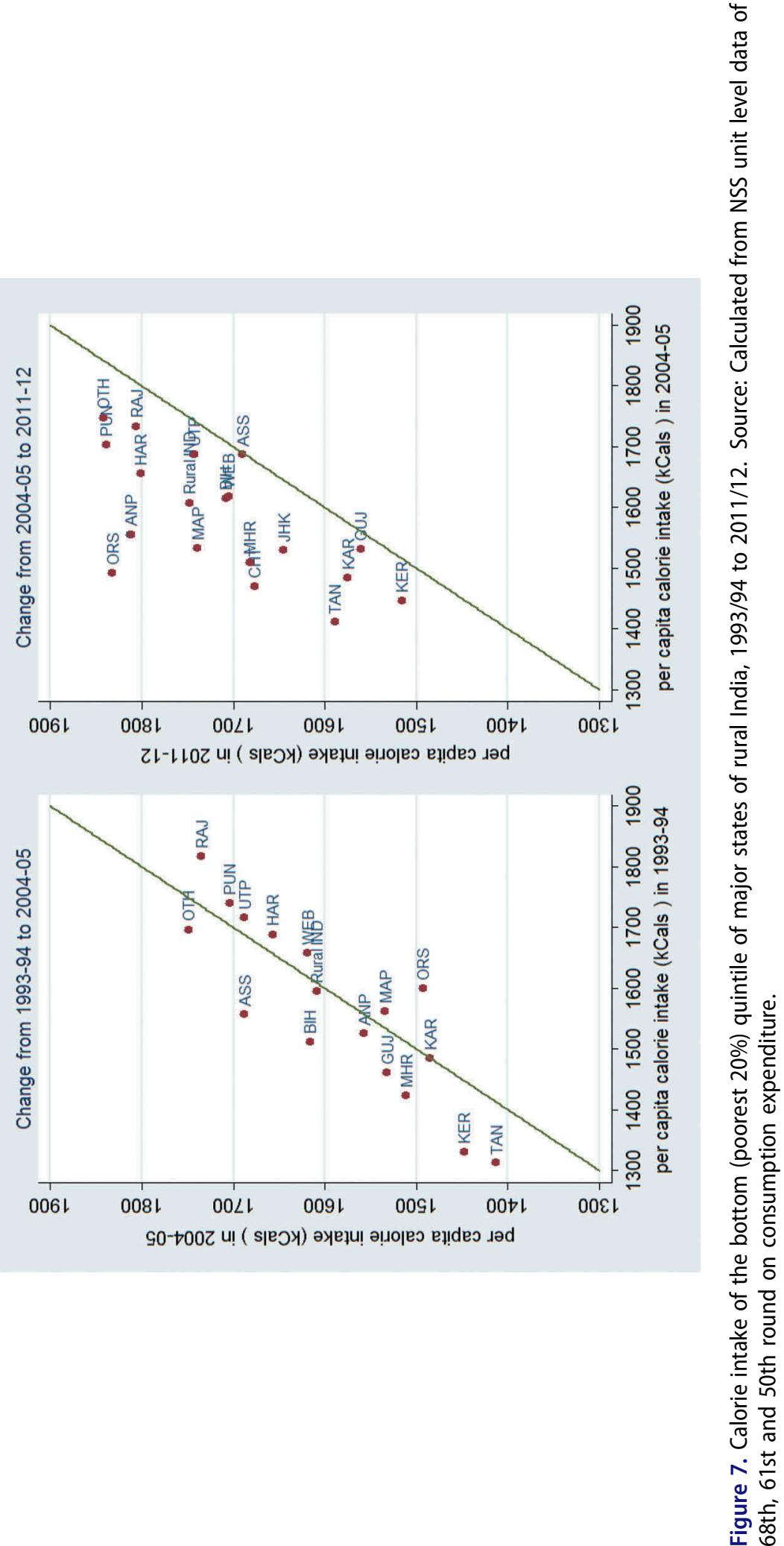


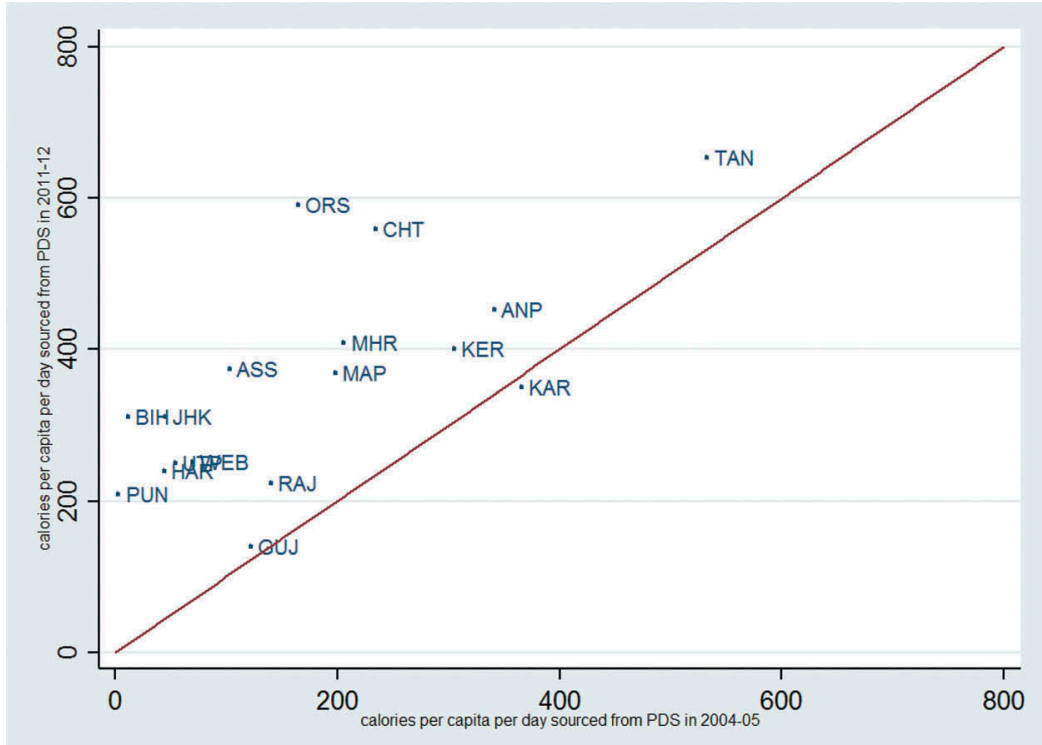

Figure 8. Calorie intake from PDS of the poorest $40 \%$ of the population of major states of rural India, 2004/05 compared with 2011/12. Source: Calculated from NSS unit level data of 68th and 61 st round on consumption expenditure.

Pradesh, Madhya Pradesh, and Chhattisgarh. Gains were weakest in Assam, Gujarat, Uttar Pradesh, Rajasthan, West Bengal, and Bihar. Increased consumption of PDS-sourced calories seems an important reason for this pattern, as indicated in Figure 8, which indicates that Chhattisgarh and Odisha are the states at the furthest top-left of the diagram, suggesting greatest improvement. In both periods, Tamil Nadu was the state that provided the bottom $40 \%$ of the population with the largest amount of calories per capita from PDS, and Maharashtra, Andhra Pradesh, and Madhya Pradesh also witnessed strong improvements.

\section{Social policy strengthening and calorie consumption turnaround}

The data discussed above beggar the question of what factors are driving changes, particularly with regards to the recorded differences in state-wise calorie consumption within the poorest quintile. The first apparent explanation that needs to be considered is economic growth. Is it the case that the states recording increased per capita calorie consumption growth among poor populations are also those with higher rates of economic growth, particularly in the rural sector? If such an association was found to be robust, it would strongly endorse the role of trickle-down effects emanating from economic liberalization. Evidence from the first decade of 

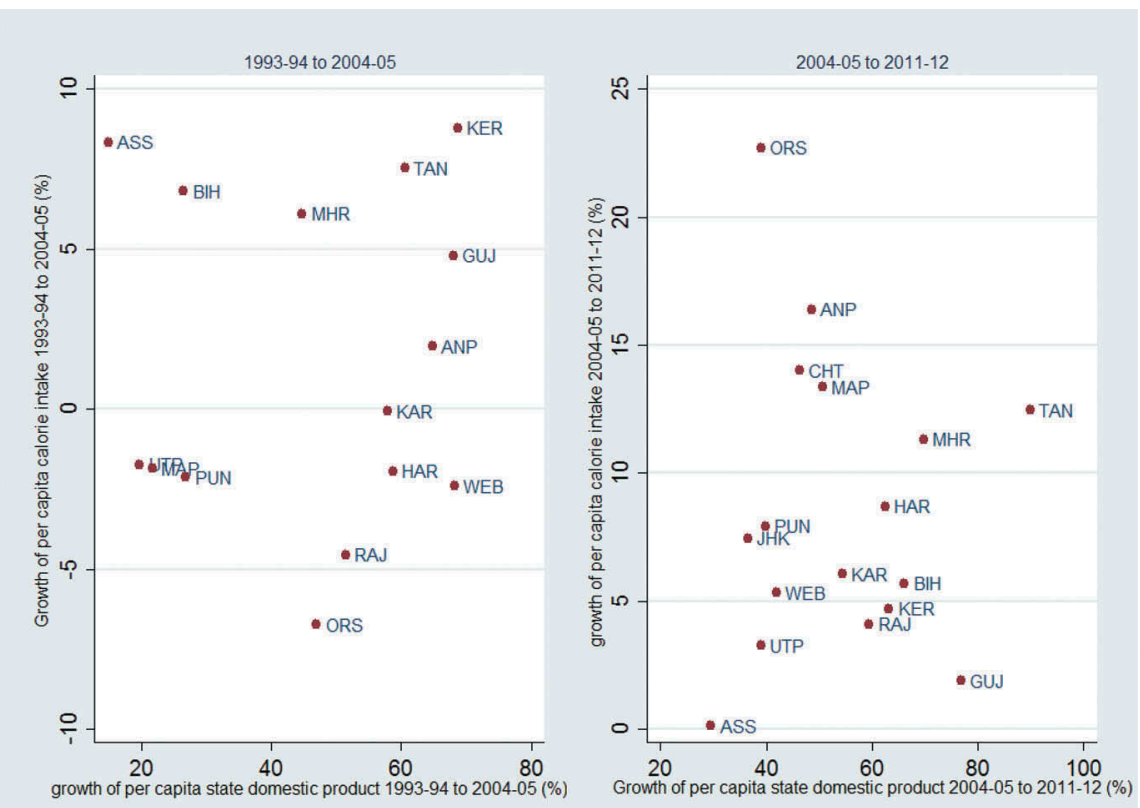

Figure 9. Scatter plot of growth in per capita calorie intake of poorest $20 \%$ and per capita state domestic product. Source: Calculated from NSS unit level data of 68th, 61st, and 50th round on consumption expenditure.

the liberalization period does not support this argument. In a study of National Family Health Survey (NFHS) data from 1992 to 2005, Subramanyam et al. ${ }^{41}$ found no relationship between economic growth and childhood undernutrition, as measured in anthropometric indicators (stunting and wasting) for infants and children. Undernutrition is a key influence in stunting and wasting, although, it needs to be noted, not the sole determinant. Our analysis of calorie consumption within the NSS database supports the argument that there is no robust relationship between economic growth and food/nutrition outcomes, in agreement with a significant body of literature addressing this same topic. ${ }^{42}$ As illustrated in Figure 9, there is no systematic state-wise relationship between growth in real per capita domestic product (valued at 2004/05 prices) and growth in per capita calorie intake of poorest $20 \%$ in rural areas for both time periods (i.e., $1993 / 94$ to $2004 / 05$ and $2004 / 05$ to 2011/12).

If the rate of a state's economic growth is not closely associated with the rate of change in per capita calorie consumption for the poorest $20 \%$ of its rural population, the next most obvious driver is the coverage and efficiency of food-based social protection schemes, in particular the PDS, as the single most important component of India's social safety net. 
Table 3. Calorie intake for bottom 40\% of the rural population by type of ration card in $2004 / 05$ and 2011/12.

\begin{tabular}{cccccccc}
\hline & Quintile & Year & Antyodaya & BPL & Others & No card & Total \\
\hline Bottom 40\% of & Poorest 20\% & $2004-05$ & 1648 & 1591 & 1633 & 1580 & 1609 \\
population & & $2011-12$ & 1820 & 1756 & 1748 & 1660 & 1748 \\
& Next poorest 20\% & $2004-05$ & 1893 & 1865 & 1887 & 1857 & 1876 \\
& & $2011-12$ & 2003 & 1962 & 1935 & 1882 & 1944 \\
Total population & & $2004-05$ & 1923 & 1920 & 2129 & 1994 & 2047 \\
& & $2011-12$ & 2021 & 2060 & 2162 & 2026 & 2099 \\
\hline
\end{tabular}

Source: Calculated from NSS unit level data of 61st and 68th round consumption expenditure.

The period leading up to the 68th NSS round coincided with a period of social protection policy strengthening. A slew of studies published since 2010, led by Reetika Khera ${ }^{43}$ provide evidence of substantial improvements to delivery ratios within the PDS. Khera ${ }^{44}$ concludes that the PDS deteriorated in the 15 years to $2004 / 05$ (total leakage increasing from $24 \%$ to $54 \%$ of the PDS supply), but from 2004/05 to 2010/11, leakages fell from 54\% to $44 \%$. While this is still high, stark improvements were recorded in some of the traditionally worst-performing states.

The data from the NSS 68th round provides support to these arguments. Table 3 provides an overview of the link between PDS entitlement (ration card status) and per capita calorie consumption for the two poorest quintiles. This Table clearly shows the pivotal importance of ration card status to the quantity of calories consumed. In 2011/12, within the poorest quintile, households with Antyodaya status (a ration card allocated to the

Table 4. Improvements in coverage of PDS for the bottom $40 \%$ of the rural population over time.

\begin{tabular}{|c|c|c|c|c|c|c|}
\hline \multirow[b]{2}{*}{ State } & \multicolumn{3}{|c|}{ Poorest $20 \%$ of households } & \multicolumn{3}{|c|}{ Next poorest $20 \%$ of households } \\
\hline & $1993 / 94$ & $2004 / 05$ & $2011 / 12$ & $1993 / 94$ & $2004 / 05$ & $2011 / 12$ \\
\hline Andhra Pradesh & 80.67 & 78.56 & 97.03 & 72.10 & 75.70 & 95.33 \\
\hline Assam & 37.49 & 19.69 & 65.83 & 21.33 & 12.15 & 55.39 \\
\hline Bihar & 3.64 & 2.96 & 62.97 & 2.72 & 1.55 & 51.78 \\
\hline Chhattisgarh & $\mathrm{N} / \mathrm{A}$ & 43.33 & 82.24 & $\mathrm{~N} / \mathrm{A}$ & 22.70 & 68.79 \\
\hline Gujarat & 50.89 & 51.82 & 55.72 & 51.95 & 40.40 & 33.43 \\
\hline Haryana & 3.08 & 6.43 & 47.13 & 3.50 & 6.01 & 21.83 \\
\hline Jharkhand & N/A & 11.59 & 60.12 & N/A & 5.85 & 34.13 \\
\hline Karnataka & 69.07 & 80.54 & 80.83 & 58.69 & 67.16 & 82.52 \\
\hline Kerala & 88.25 & 62.23 & 98.08 & 89.28 & 47.41 & 91.41 \\
\hline Madhya Pradesh & 13.85 & 37.57 & 63.70 & 10.05 & 25.32 & 47.49 \\
\hline Maharashtra & 30.50 & 45.46 & 74.16 & 41.25 & 35.03 & 56.82 \\
\hline Odisha & 8.43 & 45.19 & 85.84 & 4.06 & 24.65 & 76.94 \\
\hline Punjab & 22.05 & 0.55 & 49.25 & 17.57 & 0.28 & 31.67 \\
\hline Rajasthan & 81.10 & 22.08 & 48.51 & 78.44 & 15.85 & 31.51 \\
\hline Tamil Nadu & 2.77 & 93.63 & 98.92 & 3.30 & 91.04 & 97.72 \\
\hline Uttar Pradesh & 10.21 & 12.24 & 47.91 & 10.11 & 6.35 & 27.99 \\
\hline West Bengal & 48.63 & 24.30 & 62.30 & 45.97 & 16.11 & 52.15 \\
\hline Others & 1.40 & 48.63 & 80.25 & 0.83 & 39.36 & 81.33 \\
\hline Total & 29.08 & 35.49 & 67.22 & 27.29 & 27.98 & 54.45 \\
\hline
\end{tabular}

Source: Calculated from NSS unit level data of 61st and 68th round consumption expenditure. 
"poorest of the poor") consumed on average approximately $4 \%$ more calories than households with BPL cards (Below the Poverty Line, the next lowest card status) and $10 \%$ more calories than households with no card.

The importance of PDS is reinforced, moreover, when 50th, 61st, and 68th Round NSS data are disaggregated by the state to examine the share of PDS beneficiaries among bottom $40 \%$ population of the respective rounds (Table 4). Within the NSS, a household is defined as PDS beneficiary if that household reports any rice or wheat purchased from PDS. The table illustrates the quite dramatic increases in PDS coverage for the poorest $40 \%$ of the recipients, and especially the bottom quintile, that occurred from 2004/05 to 2011/12. As supported by Figure 8, many of the poorer and historically more poorlyperforming states, including Bihar, Madhya Pradesh, Odisha, Chhattisgarh, Jharkhand, West Bengal, and Uttar Pradesh led this turnaround. These data strongly support evidence of the improved performance of the PDS during the past decade, as discussed above. They also support the findings of parallel research by Kishore and Chakrabarti ${ }^{45}$ which finds that household food consumption levels improved in states where PDS reform efforts were strongest, and is again consistent with the data presented in Figure 8.

It is here that the national-scale analysis provided by NSS data needs complementing by detailed state-specific research, if the drivers of change are to be appropriately identified. One example is research by Puri $^{46}$ into the background of changes in Chhattisgarh, historically one of India's poorest performing states when it comes to the PDS. Puri ${ }^{47}$ and Krishnamurthy et al. $^{48}$ note how improved PDS performance was closely associated with government reforms following the 2003 election and a change of political administration. The enactment of the Chhattisgarh Public Distribution System (Control) Order 2004 mandated that Fair Price Shops be operated by Gram Panchayats, self-help groups, and local cooperatives, and that the transport of PDS supplies be undertaken in government trucks painted yellow. Further reforms in 2007 extended the PDS franchise to households that were excluded previously by administrative error, adding a further 1.9 million PDS beneficiaries in the state. Then, in 2012, the Chhattisgarh administration legislated its own version of a Food Security Act in advance of the central government, enshrining the right to food in law. A second example is provided in the study by Rahman ${ }^{49}$ of PDS reforms in the Kalahandi-Balangir-Koraput (KBK) region of Odisha, which has an extended history of hunger and starvation deaths. In 2008, the targeted PDS was replaced by universal PDS. Rahman ${ }^{50}$ finds that the move to universal PDS provision was associated with a significant improvement in both the quantity of calorie intake and the quality of diets. Both these case studies provide exemplars of the role of social protection mechanisms and political commitment for 
raising nutrition indicators, underscoring the more general arguments presented in this paper. As suggested by Krishnamurthy et al., ${ }^{51}$ improvements to PDS require "sustained reforms... coupled with political and social will."

The turnaround in trends identified by the 2011/12 data prompts the suggestion that India's calorie consumption paradox was a temporary phenomenon, relevant to the first decade or so of the liberalization period. Subsequently, the nutritional implications of economic growth in India have reverted to a pattern that is more in line with international expectations. Indeed, the accumulation of recent evidence from other quarters would seem to verify this conclusion. The Comprehensive Nutrition Survey in Maharashtra, based on a representative survey of 2,809 children under five years of age, revealed a stunting rate of $24 \%$ in 2012 , which was a marked reduction from $39 \%$ revealed in $2006 .{ }^{52}$ Stunting rates are a well-established indicator of chronic undernutrition. Haddad and Valli ${ }^{53}$ argue that this was "one of the fastest declines ever recorded".

\section{Conclusion}

This paper has made two core contributions to debate on trends in per capita calorie consumption in rural India. The first of these relates to arguments about India's calorie consumption paradox. We argue that with the addition of the 2011/12 NSS data to the historical record, the perceived significance of this problem becomes diminished. Data from the 68th round conducted in 2011/12 and released in 2014 paints a much more positive story. By no means does it suggest that India's problems of nutrition insecurity among the poor have been resolved. There is still an estimated 194.6 million undernourished persons in India, and most of these live in rural areas. ${ }^{54}$ However, in contrast to the scenario that faced the country upon the release of the 2004/05 data, at least the trend now appears to be moving in a positive direction.

The second contribution of this paper, and its most novel finding, relates to the explanation for this turnaround. In this, we attribute importance to the role of food-based social safety net programs operated by the state. Prior to liberalization, from 1972/73 to 1993/94, there was weak but positive growth in calorie intake of the bottom (poor) quintiles. The 1970s and 1980s are generally considered as a period of pro-poor spending. However, the propoor bias of government policy was ameliorated, if not compromised, by the new economic policies inaugurated after 1991. The legacy of this shift in policy direction, compounded by inattentiveness to administrative failure within the PDS, is seen in the 2004/05 NSS data, which indicate that for at least a decade after liberalization, India's poor did not obtain a calorie consumption dividend. 
Recognition of this policy failure inspired a renewed focus on food-based social welfare policies, at the national level in the UPA-II administration (2009 to 2014) and in some states, as noted in the discussion of Chhattisgarh, above. Interpretation of the NSS data from 2011/12, as well as other recent sources cited earlier in this paper, suggests that these initiatives may now be bearing benefits.

It is important that the findings reported in this paper are not be interpreted in such a way as to engender complacency in India's nutrition challenge. Hunger remains a pervasive characteristic across much of India's rural population, and the effects of undernutrition provide both a human rights failure and a drag on the country's economic growth. Yet there is evidence that the strengthening of social protection mechanisms relating to food that has occurred in India during the past decade is, at last, producing a nutrition dividend. The release of further, more recent data is required to verify the duration and strength of these directions of change.

\section{Notes}

1 Jagdish Bhagwati and Arvind Panagariya, Why Growth Matters: How Economic Growth in India Reduced Poverty and the Lessons for Other Developing Countries (New York: Public Affairs, 2013).

2 Reeve Venneman and Amaresh Dubey, "Horizontal and Vertical Inequalities in India," in Income Inequality: Economic Disparities and the Middle Class in Affluent Countries, ed. Janice.C. Gornick and Markus Jantti (Palo Alto: Stanford University Press, 2013).

3 Amit Basole and Deepankar Basu, "Fuelling Calorie Intake Decline: Household-Level Evidence from Rural India," World Development 68 (2015); Angus Deaton and Jean Dréze, "Food and Nutrition in India: Facts and Interpretations," Economic and Political Weekly 44, no. 7 (2009).

4 We note that measures of childhood stunting and wasting are not solely determined by calorie consumption levels. As suggested by Deaton and Drèze (2009: 43) "just as there is no tight link between incomes and calorie consumption, there is no tight link between the number of calories consumed and nutritional or health status." Evidently, the quality of diets, hygiene, and health are also crucially important in determining these nutritional indicators. Nevertheless, the debate on nutrition cannot ignore the fundamental role of calorie intake, and measurements of average calorie consumption represent a vital proxy for a wider discussion on this point.

5 International Institute for Population Studies (IIPS), "Comprehensive Nutrition Survey in Maharashtra," (Mumbai: IIPS, 2012).

6 Abhijeet Singh, Albert Park, and Stefan Dercon, "School Meals as a Safety Net: An Evaluation of the Midday Meal Scheme in India," Economic Development and Cultural Change 62, no. 2 (2014).

7 Sunny Jose and K. S Hari, "Progress in Reducing Child Undernutrition: Evidence from Maharashtra," Economic and Political Weekly 50, no. 3 (2015).

8 Food and Agriculture Organisation (FAO), The State of Food Insecurity in the World 2015, (Rome: FAO, 2015), www.fao.org.

9 Art Kraay, David Dollar and Tatjana Kleineberg "Growth, Inequality, and Social Welfare: Cross-Country Evidence”, Economic Policy Sixtieth Panel Meeting Hosted 
by the Einaudi Institute for Economics and Finance (EIEF), supported by Banca d'Italia: Rome, 24-25 October (2014).

10 Deaton and Dréze, "Food and Nutrition in India: Facts and Interpretations."

11 "Food and Nutrition in India: Facts and Interpretations."

12 Lawrence Haddad et al., "Reducing Child Malnutrition: How Far Does Income Growth Take Us?” World Bank Economic Review 17, no. 1 (2003).

13 Bill Pritchard, Anu Rammohan, Madhushree Sekher, S. Parasuraman and Chetan Choithani, Feeding India: Livelihoods, Entitlements, and Capabilities (London: Earthscan, 2014), 2.

14 Lawrence Haddad, "Nutrition Sensitive Economic Growth: What it is, Why it Matters, and How to encourage it", in The Handbook of Food and Nutrition Security, ed. Bill Pritchard, Rodomiro Ortiz and Meera Shekar (London: Routledge, 2016), 240-50.

15 Stuart Gillespie and Suneetha Kadiyala, "Exploring the Agriculture-Nutrition Disconnect in India," in Leveraging Agriculture for Improving Nutrition and Health, 2020 Conference Brief 20 (Washington: International Food Policy Research Institute, 2011).

16 S Subramanian and D Jayaraj, "Growth and Inequality in the Distribution of India's Consumption Expenditure: 1983 to 2009-10," Economic and Political Weekly 50, no. 32 (2015).

17 The NAS provides an estimate of private consumption through imputations of expenditure based on formulas and coefficients between different economic sectors. Therefore, NAS estimates are contingent on the accuracy of a large body of diversely collected data estimates that are modeled according to a complex set of conventions, and which, in some cases at least, are often decades old and can be highly obsolete in the context of a fast-moving economy.

18 Government of India, "Report of the Expert Group to Review the Methodology for Measurement of Poverty," (New Delhi: Planning Commission, Government of India, 2014).

19 "Report of the Expert Group to Review the Methodology for Measurement of Poverty."

20 Abhijet Sen, "Estimates of Consumer Expenditure and Its Distribution: Statistical Priorities after NSS 55th Round," Economic and Political Weekly 35, no. 51 (2000); NSSO Expert Group, "Suitability of Different Reference Periods for Measuring Household Consumption: Results of a Pilot Survey," Economic and Political Weekly 38, no. 4 (2003).

21 Deaton and Dréze, "Food and Nutrition in India: Facts and Interpretations," ibid.44, no. 7 (2009).

22 Shari Eli and Nicholas Li, "Can Caloric Needs Explain Three Food Consumption Puzzles? Evidence from India," (University of Toronto, 2012), www.dartmouth.edu.

23 Basole and Basu, "Fuelling Calorie Intake Decline: Household-Level Evidence from Rural India."

24 Md Zahid Siddiqui and Swastika Chakraborty, Inequality in Access to Modern Energy Services: Indian Case (Indian Council of Social Science Research, 2014), Mumbai, India.

25 Abjit Banerjee and Ester Duflo, "More Than 1 Billion People Are Hungry in the World," Foreign Policy 186 (2011); Poor Economics: A Radical Rethinking of the Way to Fight Global Poverty (New York: Public Affairs, 2011).

26 Frederic Landy, "India, 'Cultural Diversity' and the Model of Food Transition," Economic and Political Weekly 44, no. 20 (2009).

27 “India, 'Cultural Diversity' and the Model of Food Transition."

28 Surjit Bhalla, "Inclusion and Growth in India: Some Facts Some Conclusions, Lse Asia Research Centre," (Working Paper 39, vol. 39, LSE, London, 2011). 
29 Planning Commission of India, Performance Evaluation of Targeted Public Distribution System (New Delhi: Government of India, 2005).

30 Sikha Jha and Bharat Ramaswami, "How Can Food Subsidies Work Better? Answers from India and Philippines', (Asian Development Bank Working Paper 221, ADB, Manila, 2010), www.adb.org.

31 Lisa C. Smith, "The Great Indian Calorie Debate: Explaining Rising Undernourishment During India’s Rapid Economic Growth,” Food Policy 50 (2015).

32 Raghav Gaiha, Raghbendra Jha, and Vani S. Kulkarni, "Demand for Nutrients in India: 1993 to 2004," Applied Economics 45, no. 14 (2013).

33 Smith, "The Great Indian Calorie Debate: Explaining Rising Undernourishment During India's Rapid Economic Growth.”

34 Bill Pritchard, Anu Rammohan, and Madhushree Sekher, "Food Security as a Lagging Component of India's Human Development: A Function of Interacting Entitlement Failures.," Journal of South Asian Studies 36, no. 2 (2013).

35 National Sample Survey Office (NSSO), Nutritional Intake in India 2011-12 (Report Number 560), (New Delhi: Government of India, 2014).

36 One gram of fat is equivalent to $9 \mathrm{kcals}$ of calorie and one gram of protein is equivalent to 4 kcals of calorie.

37 M.H Suryanarayana, Nutritional Norms for Poverty: Issues and Implications (Mumbai: Indira Gandhi Institute of Development Research 2013), www.ideas.repec.org.35.

38 Nutritional Norms for Poverty: Issues and Implications. 35.

39 Deaton and Dréze, "Food and Nutrition in India: Facts and Interpretations."

40 Note that only the major states are considered separately with the remainder is classified as "Other". Also note that for the first period (from 1993/94 to 2004/05) Jharkhand and Chhattisgarh are not separately indicated because for part of this time they were part of Bihar and Madhya Pradesh, respectively.

41 Malavika A. Subramanyam, Ichiro Kawachi, Lisa F. Berkman, S.V. Subramanian, "Is Economic Growth Associated with Reduction in Child Undernutrition in India?," PLOS Medicine 8, no. 3 (2011).

42 B. Viswanathan and J.V. Meenakshi, "The Changing Pattern of Undernutrition in India: A Comparative Analysis across Regions”, (Research Paper No. 2006/118, Finland: UNU World Institute for Development Economics Research, 2006); Ramesh Chand and Jaya Jumrani, "Food Security and Undernourishment in India: Assessment of alternative Norms and the Income Effect", ICAR Policy Brief 38 (2013); Josephine Duh and Dan Spears, "Health and Hunger: Disease, Energy Needs, and the Indian Calorie Consumption Puzzle. The Economic Journal 127, no. 606 (2017): 2378-409; Md Zakaria Siddiqui, Ronald Donato and Jaya Jumrani, "Looking Past the Indian Calorie Debate: What is Happening to Nutrition Transition in India." The Journal of Development Studies (2017): 1-20; Narayanan, Sudha, and Nicolas Gerber. "Social Safety Nets for Food and Nutrition Security in India," Global Food Security (2017), 15: 65-76.

43 Rheetika Khera, "India's Public Distribution System: Utilisation and Impact," Journal of Development Studies 47, no. 7 (2011); "Revival of the Public Distribution System: Evidence and Explanations," Economic and Political Weekly 46, no. 44-45 (2011); "Revival of the Pds and the Cash Alternative," in Growth Week Conference (London: London School of Economics, 2012); "Putting Kerala to Work," The Hindu, August 1, 2012.

44 "India's Public Distribution System: Utilisation and Impact."

45 Avinash Kishore and Sunam Chakrabarti, "Is More Inclusive More Effective? The 'New Style’ Public Distribution System in India," Food Policy 55 (2015). 
46 Raghav Puri, "Reforming the Public Distribution System: Lessons from Chhattisgarh," Economic and Political Weekly 48, no. 5 (2012).

47 "Reforming the Public Distribution System: Lessons from Chhattisgarh."

48 Krishnamurthy, Prasad, Vikram Pathania, and Sharad Tandon. "Food Price Subsidies and Nutrition: Evidence from State Reforms to India's Public Distribution System." Economic Development and Cultural Change 66, no. 1 (2017): 55-90.

49 Andaleeb Rahman, "Universal Food Security Program and Nutritional Intake: Evidence from the Hunger Prone Kbk Districts in Odisha," Food Policy 63 (2016).

50 "Universal Food Security Program and Nutritional Intake: Evidence from the Hunger Prone KBK Districts in Odisha."

51 Prasad Krishnamurthy, Vikram Pathania, and Sharad Tandon, "Public Distribution System Reforms and Consumption in Chhattisgarh: A Comparative Empirical Analysis," Economic and Political Weekly 49, no. 8 (2014): 74.

52 International Institute for Population Studies (IIPS), "Comprehensive Nutrition Survey in Maharashtra."

53 Lawrence Haddad and Elsa Valli, "Maharashtra's Rapid Decline in Stunting Rates between 2006 and 2012: What Do the Survey Data Tell Us?" in Maharashtra's Child Stunting Declines: What Is Driving Them? Findings of a Multidisciplinary Analysis, ed. Lawrence Haddad, et al. (Brighton, UK: Institute of Development Studies, 2014), 28.

54 Food and Agriculture Organisation (FAO), The State of Food Insecurity in the World 2015.

\section{Disclosure statement}

No potential conflict of interest was reported by the authors.

\section{Funding}

The research for this paper was funded by the Australian Research Council, project 'Farmers of the Future' (DP140101682)

\section{Notes on contributors}

Bill Pritchard is Professor of Human Geography at the University of Sydney.

Kuntala Lahiri-Dutt is Professor, Resource, Environment and Development Program at the Crawford School of Public Policy at the Australian National University.

Md Zakaria Siddiqui is an Adjunct Fellow at the University of South Australia.

\section{Appendix. Glossary of acronyms for India States}

ANP Andhra Pradesh

ASS Assam

BIH Bihar

CHT Chhattisgarh

GUJ Gujarat 
HAR Haryana

JHK Jharkhand

KAR Karnataka

KER Kerala

MAP Madhya Pradesh

MHR Maharashtra

ORS Odisha

PUN Punjab

RAJ Rajasthan

TAN Tamil Nadu

UTP Uttar Pradesh

WEB West Bengal

OTH Others 